Lili Xin $ه$

Jihui Liang

https://doi.org/10.21278/TOF.43Si104

ISSN 1333-1124

eISSN 1849-1391

\title{
A DYNAMIC ANALYSIS ON THE POTATO CONVEYING AND SEPARATION SYSTEM CONSIDERING THE ACTING FORCE OF A MATERIAL
}

\begin{abstract}
Summary
The acting forces between soil and potatoes in the process of harvesting by vibration loads are complicated. In order to study the effect of the exciting forces for the dynamic characteristics of potato conveying and vibration separation system, taking potatoes with soil on them and equivalent viscoelastic material as a whole, a mechanic model was establish for the potato conveying and separation system considering the sectional material forces between the potatoes, the soil and the shaker chain in the conveying, separating, crushing and screening process, and then analysis of the model was conducted by asymptotic method numerical integration. The results show that the dynamic characteristic of the conveying and separation system is more complicated under specific conditions, and the system motion is chaotic. The test further shows that the rational use of vibration can improve the separation rate of potato and soil, and improve the harvest quality.
\end{abstract}

Key words: $\quad$ Conveying and separation system of potatoes; Exciting force; Nonlinear dynamics; Chaotic

\section{Introduction}

In the field of agricultural engineering, research on potato harvester vibration friction both at home and abroad mainly focus on the kinematic analysis of the potatoes as the key parts, the research and development of potato harvester and how to reduce mechanical damage to the potatoes during the harvest.

In terms of research on the kinematics analysis of the potatoes as the key components, Jia Jingxia et al. carried out a computer simulation for the motion process of the materials on the vibration sieve, and obtained the motion change of the materials on the sieve surface. However, the effect of the elasticity of the potato tuber and other factors of the motion process were not taken into account. Zhang Jian et al. conducted the motion simulation for the virtual prototype of potato harvester jitter separation device with ADAMS, and the results showed that with a separator installation angle of $17^{\circ}$, the jitter frequency was $8.89 \mathrm{~Hz}$, the long and short axis radius were $69 \mathrm{~mm}$ and $55 \mathrm{~mm}$, respectively, most of the vertical average speeds of the centroid of the potatoes were less than or equal to $468 \mathrm{~mm} / \mathrm{s}$, the horizontal speeds fell 
within the range of $1342-1530 \mathrm{~mm} / \mathrm{s}$, and the conveying process was smooth, which could meet the design requirements [1-7]. Shi Mingming et al. designed the 4U-1400 type potato harvester, and determined the key parameters of each device through kinematic analysis and testing. This machine is equipped with functions including potato digging, separation of potato and soil, separation of the potato seedling, weeds and residual membrane, vertical lifting and bagging in 2 rows at a time [8-9].

As for studies on the development of the potato harvester, Liu Bao et al. designed the MZPH-820 type single-row potato harvester with some new features. For example, it has adjustable digger blade angle, flexible guiding supporting wheels of the lifting chain which could move upward with the support of cantilever plate [10]. Zhang Hua et al. designed the 4UM-640 type vibrating potato digger. With a grid digging device and an eccentric rocker vibrating digging mechanism, this machine could perform potato digging and harvest in different profound adjustments with a screw type digger blade [11]. Shi Linrong et al. developed a disc grid type potato digger compatible with the 4-wheel tractor, which integrated the grid type digging device and disc grid type separation device, and improved disc cutter structure, which was convenient for leaving out the fine soil on the side when cutting through the soil [12]. Wu Jianmin et al. designed a poke finger's wheel type potato digger compatible with the walking tractor, featuring the combined use of a grid type digging device and a poke finger's wheel type separation device [13-15].

For the study on reducing the mechanical damage to potatoes during the harvesting process, the research by W. S. Kang et al. showed that given a fixed driving speed of the tractor, increasing frequency could improve the working quality of the digger blade and the soil separation rate. Under a new and fixed working condition of $6 \mathrm{~mm}$ amplitude, $14 \mathrm{~Hz}$ frequency, and $2.12 \mathrm{~km} / \mathrm{h}$ speed, a result of high potato harvest rates and low the damage rates was achieved [16, 17]. The results of M. Bentini's et al. test and research showed that the forward speed of the potato harvester and soil moisture content could affect the strength and damage of tubers. With wet soil, the impact strength and damage by the mechanical components of the potato harvester for the potatoes could be reduced. When the soil is dry, the mechanical components had bigger impact strength, so the tubers were more likely to be damaged $[18,19]$. D. C. McRAE developed a potato harvester conveyor belt at a controllable unloading height, and this conveyor belt could reduce the damage to potatoes in the conveying process. In the process of conveying the potatoes from the harvester to the trailer, the conveying components had a sensor installed at the end of the conveying belt to detect the unloading height. By driving the solenoid valve to operate hydraulic lifting and descending, the control of unloading height was achieved [20-25].

In this paper, with the Runge-Kutta method, an experiment was carried out to find a plausible theory and numerical solution for the potato conveying and separation system considering the segment soil acting force of collision and friction. Based on the test findings, the impact of exciting force on the nonlinear dynamic characteristics of the system and the separation rate of potato and soil was further studied.

\section{Material and Methods}

A simplified model of the conveying and separation system of potatoes is shown in Figure 1. In the model, potatoes with soil were chosen as a viscoelastic material.

The system dynamics differential equation in y direction is:

$$
M \ddot{y}+c_{p} \dot{y} \sin \alpha+k_{p} y \sin \alpha+r(y) \sin \alpha+F_{p}(\ddot{y}, \dot{y}, y)=m e \omega^{2} \sin \omega t \sin \alpha
$$

where, $\omega=2 \pi f, F(t)=m e \omega^{2} \sin \omega t, M$ is the conveyor chain mass, $c_{p}$ is the equivalent 
damping of soil, $k_{p}$ is the equivalent stiffness of soil, $F_{p}(\ddot{y}, \dot{y}, y)$ is the acting force of material, $r(y)$ is the elasticity restoring force, $m$ is eccentric mass, $e$ is eccentricity, $\omega$ is angular velocity, $f$ is vibration frequency, $F(t)$ is exciting force, and $y$ is horizontal displacement.

$$
r(y)=\left\{\begin{array}{l}
\eta\left(y-y_{0}\right)^{2}-\eta y+B_{1}, \dot{y}>0 \\
\eta\left(y+y_{0}\right)^{2}-\eta y-B_{1}, \dot{y}<0
\end{array}\right.
$$

where, $y_{0}$ is the deformation of material, $\eta$ and $B_{1}$ are constants, of which $\eta$ is the index of hysteresis.

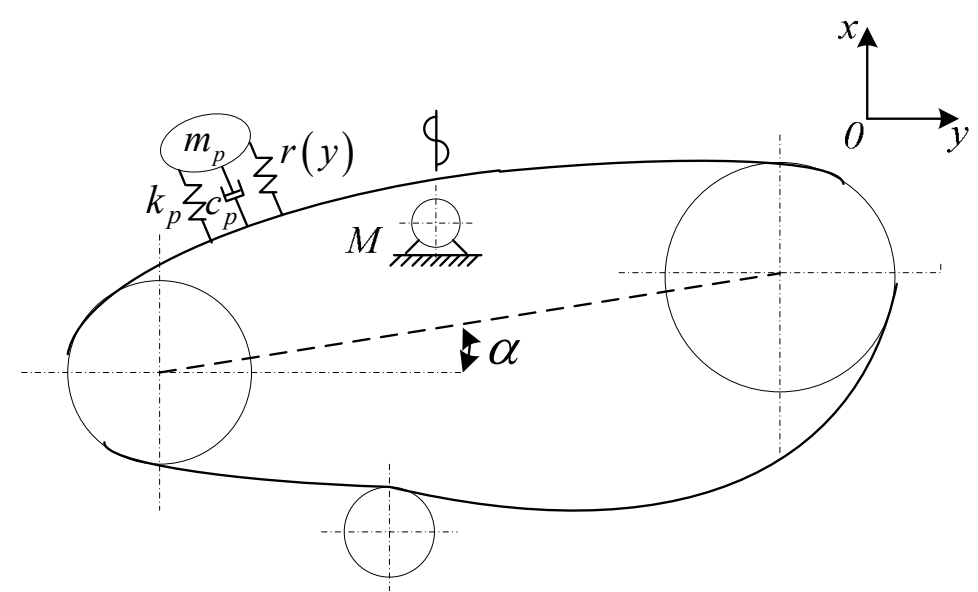

Fig. 1 Simplified model of conveying and separation system of potatoes

In the conveying process, the potatoes with soil and vines sometimes move forward, and sometimes backward, but the overall direction of the conveyed materials within a cycle of vibration is backward until the potatoes fall to the ground.

When the materials move forward or backward, because the friction forces between the materials and the conveying chain are different, the nonlinear force in y direction is divided into three parts. The first part is the inertia force in section, namely the material acting force during the motion between material and working surface, when the reverse sliding termination is to forward sliding beginning and the forward sliding termination is to reverse sliding beginning; the second and the third parts are the section friction force, in other words, the force of materials operating on the working surface serves as the sliding friction force, when the forward sliding beginning is to forward sliding termination and the reverse sliding beginning is to reverse sliding termination.

The section soil reaction equation is as below:

$$
F_{p}(\ddot{y}, \dot{y}, y)=\left\{\begin{array}{l}
m_{p} \ddot{y} \cos \alpha, \varphi_{r \varepsilon}-2 \pi \leq \varphi \leq \varphi_{f s}, \varphi_{f \varepsilon} \leq \varphi \leq \varphi_{r s} \\
-m_{p} f(g+\ddot{y} \sin \alpha), \varphi_{f s} \leq \varphi \leq \varphi_{f \varepsilon} \\
m_{p} f(g+\ddot{y} \sin \alpha), \varphi_{r s} \leq \varphi \leq \varphi_{r \varepsilon}
\end{array}\right.
$$

where, $\varphi_{r \varepsilon}$ is the initial angle of the opposite direction, $\varphi_{f s}$ is the termination angle of the positive direction, $\varphi_{f \varepsilon}$ is the initial angle of the positive direction, $\varphi_{r s}$ is the termination angle of the opposite direction. 
By using the asymptotic method to solve the Equation (1), the first approximate solution of the system in the primary resonance state can be set as:

$$
y=a \cos (\omega t+\theta)=a \cos \psi
$$

where, $a$ is the amplitude, $\theta$ is the phase angle.

$$
\begin{aligned}
& f_{0}(a, \psi)=F_{p}\left(-a \omega^{2} \cos \psi,-a \omega \sin \psi, a \cos \psi\right) \cos \alpha \\
& \frac{\mathrm{d} a}{\mathrm{~d} t}=-\frac{f a}{2 M}-\frac{1}{2 \pi M \omega} \int_{0}^{2 \pi} f_{0}(a, \psi) \sin \psi \mathrm{d} \psi-\frac{k_{0} e \sin \alpha \cos \theta}{M \omega a} \\
& \frac{\mathrm{d} \theta}{\mathrm{d} t}=\omega-\frac{1}{2 \pi M a \omega} \int_{0}^{2 \pi} f_{0}(a, \psi) \cos \psi \mathrm{d} \psi-\frac{k_{0} e \sin \alpha \sin \theta}{M \omega a}
\end{aligned}
$$

where,

$$
K_{m}=\sin ^{2} \alpha-\frac{b_{1} \cos \alpha}{m_{p} \omega^{2} a}, \quad f_{m}=\frac{a_{1} \cos \alpha}{\omega a}
$$

where,

$$
\begin{aligned}
a_{1}= & \frac{m_{p} \omega^{2} a}{\pi}\left\{-\frac{1}{2} \cos \alpha \sin ^{2} \phi\left(\left|\begin{array}{l}
\phi_{f s} \\
\phi_{r e}-2 \pi
\end{array}-\right| \begin{array}{l}
\phi_{r s} \\
\phi_{f e}
\end{array}\right)-f\left[\frac{g}{\omega^{2} a} \sin \phi-\frac{1}{2} \sin ^{2} \phi \sin \alpha\right] \mid \begin{array}{l}
\phi_{f e} \\
\phi_{f s}
\end{array}\right. \\
& \left.+f\left[\frac{g}{\omega^{2} a} \sin \phi-\frac{1}{2} \sin ^{2} \phi \sin \alpha\right] \mid \begin{array}{l}
\phi_{r e} \\
\phi_{r s}
\end{array}\right\} \\
b_{1}= & \frac{m_{p} \omega^{2} a}{\pi}\left\{-\frac{1}{2} \cos \alpha\left(\phi-\frac{1}{2} \sin 2 \phi\right)\left(\begin{array}{l}
\phi_{f s} \\
\phi_{r e}-2 \pi
\end{array}+\mid \begin{array}{l}
\phi_{r s} \\
\phi_{f e}
\end{array}\right)+f\left[-\frac{g}{\omega^{2} a} \sin \phi-\frac{1}{2} \sin \alpha\left(\phi-\frac{1}{2} \sin 2 \phi\right)\right] \mid \begin{array}{l}
\phi_{f e} \\
\phi_{f s}
\end{array}\right. \\
+ & \left.f\left[-\frac{g}{\omega^{2} a} \cos \phi-\frac{1}{2} \sin \alpha\left(\phi-\frac{1}{2} \sin 2 \phi\right)\right] \mid \begin{array}{l}
\phi_{r e} \\
\phi_{r s}
\end{array}\right\}
\end{aligned}
$$

Thus

$$
\begin{aligned}
& a=\frac{m \omega^{3} \cos \theta}{k_{p}+m \omega^{2}-\left[M+\left(\sin ^{2} \alpha-\frac{b_{1} \cos \alpha}{m_{p} \omega^{2}}\right) M\right] \omega^{2}} \\
& \theta=\arctan \frac{f+\frac{a_{1}}{\omega a} \cos \alpha}{k_{p}+m \omega^{2}-\left[M+\left(\sin ^{2} \alpha-\frac{b_{1} \cos \alpha}{m_{p} \omega^{2}}\right) m_{p}\right] \omega^{2}}
\end{aligned}
$$

The numerical simulation research of the system is carried out by using the fourth-order Rounge-Kutta method.

The basic parameters of the potato conveying and separation system are: $M=125 \mathrm{~kg}, m_{p}=0.133 \mathrm{~kg}, k_{p}=1526 \mathrm{~N} / \mathrm{m}, c_{p}=20.44 \mathrm{~N} \cdot \mathrm{s} / \mathrm{m}, \eta=4, y_{0}=0.0005 \mathrm{~m}, B_{1}=200$, $f=0.4, g=9.8 \mathrm{~m} / \mathrm{s}^{2}, \alpha=10^{\circ}$. 
Take $u=M y, \tau=\omega_{0} t, v=\frac{\omega}{\omega_{0}}, \omega_{0}=\frac{k_{p}}{M}$.

Equation (1) is dimensionless to be:

$$
\ddot{u}+\frac{c_{p} \sin \alpha}{M \omega_{0}} \dot{u}+\frac{k_{p} \sin \alpha}{M \omega_{0}^{2}} u+\frac{\sin \alpha}{\omega_{0}^{2}} r(u)+\frac{1}{\omega_{0}^{2}} F_{p}(\ddot{u}, \dot{u}, u)=m e v^{2} \sin \alpha \sin v t
$$

where,

$$
\begin{aligned}
& r(u)=\eta\left(\frac{1}{M} u-\frac{\omega_{0} u_{0}}{M^{2}} \operatorname{sgn}(\dot{u})\right)^{3}-\frac{\eta}{M} u+\frac{B_{1} \omega_{0}}{M} \operatorname{sgn}(\dot{u}) \\
& F_{p}(\ddot{u}, \dot{u}, u)=\left\{\begin{array}{l}
\frac{m_{p} \omega_{0}^{2} \cos \alpha}{M} \ddot{u}, \varphi_{r \varepsilon}-2 \pi \leq \varphi \leq \varphi_{f s}, \varphi_{f \varepsilon} \leq \varphi \leq \varphi_{r s} \\
-m_{p} f\left(g+\frac{\omega_{0}^{2} \sin \alpha}{M} \ddot{u}\right), \varphi_{f s} \leq \varphi \leq \varphi_{f \varepsilon} \\
m_{p} f\left(g+\frac{\omega_{0}^{2} \sin \alpha}{M} \ddot{u}\right), \varphi_{r s} \leq \varphi \leq \varphi_{r \varepsilon}
\end{array}\right.
\end{aligned}
$$

When the exciting forces are $0.05,0.058,0.063,0.089,0.13$, and 0.22 , respectively, the trajectory in the phase plane is shown in (a) (f) in Figure 2.

\section{Results}

In the experiments, the potato conveying and separation device, the electronic scales and the vibration test system were used as the main instruments. The electronic scales are used to measure the mass of the potatoes before and after conveying, and the vibration test system for testing the system vibration under different conditions.

The measured mass of the potatoes before and after conveying under different exciting forces are shown in Table 1.

Table 1 Potato mass before and after the separation.

\begin{tabular}{ccccc}
\hline Conditions & $\begin{array}{c}\text { Exciting force } \\
/ \mathrm{kN}\end{array}$ & $\begin{array}{c}\text { Potato mass before } \\
\text { the separation } \\
/ \mathrm{kg}\end{array}$ & $\begin{array}{c}\text { Potato mass after } \\
\text { the separation } \\
/ \mathrm{kg}\end{array}$ & $\begin{array}{c}\text { Separation rate } \\
\text { of potato and soil } \\
/ \%\end{array}$ \\
\hline 1 & 1 & 2 & 1.828 & 91.4 \\
2 & 1.12 & 2 & 1.866 & 93.3 \\
3 & 1.4 & 2 & 1.884 & 94.2 \\
4 & 1.71 & 2 & 1.892 & 94.6 \\
5 & 2 & 2 & 1.914 & 95.7 \\
6 & 2.4 & 2 & 1.942 & 97.1 \\
7 & 2.7 & 2 & 1.93 & 96.5 \\
8 & 3.2 & 2 & 1.912 & 95.6 \\
9 & 3.9 & 2 & 1.904 & 95.2 \\
\hline
\end{tabular}

\section{Discussion}

From Figure 2 it can be obserbed that the trajectories of (a)-(f) are all the closed curves, and closed by 1 circle, 2 circles, 3 circles, 4 circles and 8 circles, respectively. With the increase of the exciting forces, the change process of system oscillation changed from $\mathrm{T}$ to $2 \mathrm{~T}, 3 \mathrm{~T}$. 
$22 \mathrm{~T}, \ldots 2 \mathrm{nT}$. When the exciting force is $0.05 \mathrm{kN}$, the system period is $1 \mathrm{~T}$ phase-locked oscillation. When the exciting force is $0.058 \mathrm{kN}$, the system period is $2 \mathrm{~T}$ phase-locked oscillation. When the exciting force is $0.063 \mathrm{kN}$, the system period is $3 \mathrm{~T}$ phase-locked oscillation. When the exciting force is $0.089 \mathrm{kN}$, the system period is $4 \mathrm{~T}$ phase-locked oscillation. When the exciting force is $0.13 \mathrm{kN}$, the system period is $8 \mathrm{~T}$ phase-locked oscillation. When the exciting force is $0.22 \mathrm{kN}$, the system is in chaotic motion.

In the conveying and separation process, due to the collision between the potatoes, the clods and the belt, the clods attached to the potatoes begin to break, which indicates that a very complex interaction between them takes place on the conveying separating device. At vibration loads attached on potato soil is broken into loose particles, just have attached the equivalent of potato degree and equivalent damping change, when the exciting force to a certain value, the system enters into a chaotic and nonlinear motion state.

The data from Table 1 shows that when the exciting force is relatively small, the separation rate of potato and soil is relatively low. When the exciting force is $2.7 \mathrm{kN}$, the separation rate of potato and soil reached the highest level. When the exciting force is a fixed value, the system enters into a chaotic and nonlinear motion state. This conclusion is consistent with the theoretical analysis, showing that the reasonable use of vibration can improve the separation rate of potato and soil.

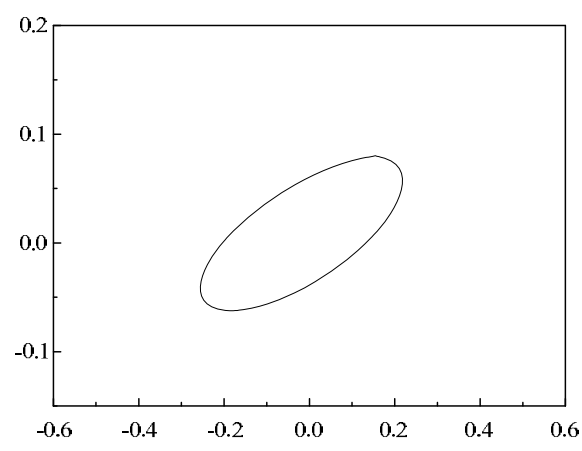

(a)

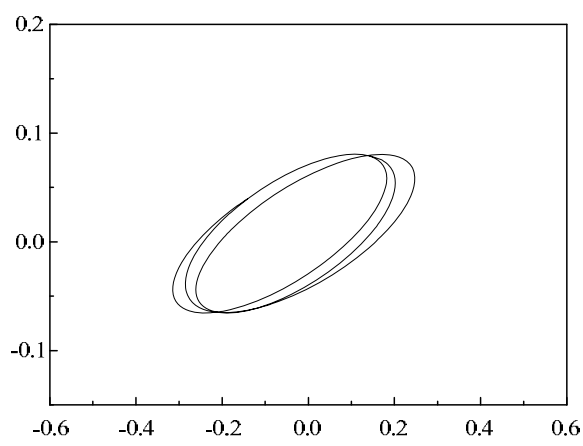

(c)

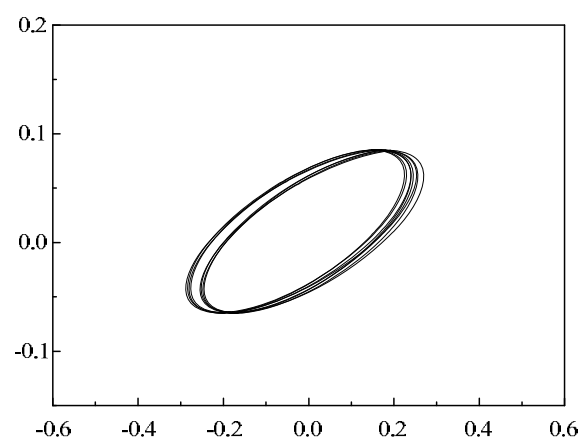

(e)

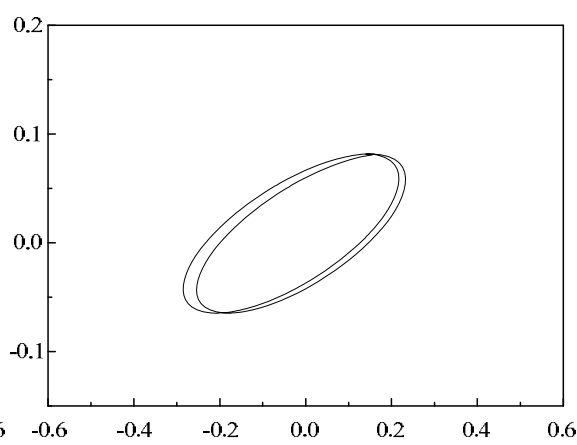

(b)

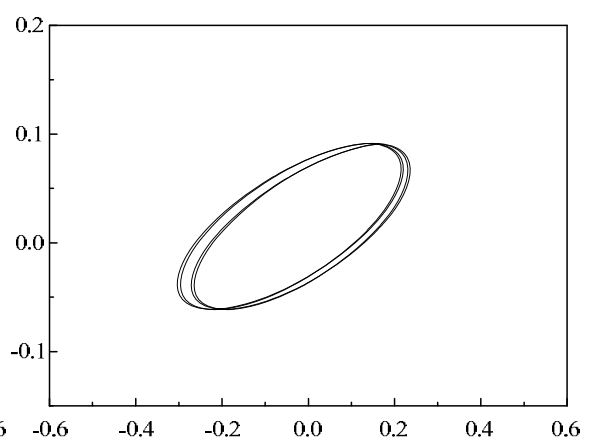

(d)

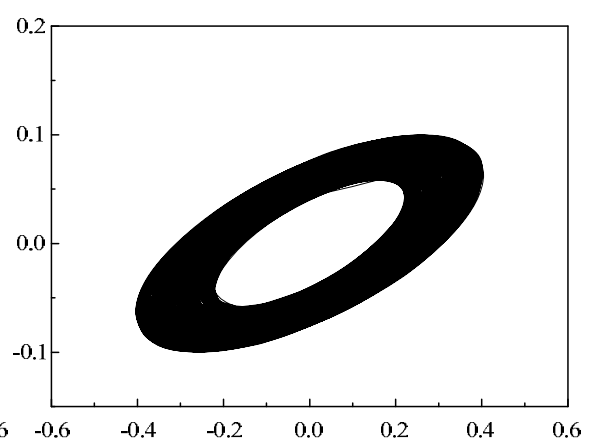

(f)

Fig. 2 The trajectory in the phase plane 


\section{Conclusion}

This paper established a dynamic model of potato conveying and separation system considering the material acting force, resorted to both theoretical knowledge and numerical simulation to aid the analysis, and then drew the conclusion that the system entered into a chaotic and nonlinear motion state when the exciting force was set at a given value.

In the process of conveying and separation, the potatoes with soil were in close contact with the conveying and separation device, so the potatoes moved together with the conveying and separation device. As vibration continues, the potatoes would jump, and intermittent collisions between the potatoes and the device start to takes place. The vibration of system exhibited singularity behavior. Theoretical analysis and experimental study showed that the parameters of exciting forces had a great effect on the separation of potatoes and soil. When the exciting force reached a certain fixed value, the system entered into a chaotic and nonlinear motion state, and the separation rate of potato and soil was high. The reasonable use of vibration can improve the separation rate of potato and soil, thus improving the quality of potato harvest.

\section{Acknowledgements}

This work is financially supported by the Talent Plan of Liaoning Province, by the Cultivation Plan for Youth Agricultural Science and Technology Innovative Talents of Liaoning Province and by the National Natural Science Foundation of China under Grant No.51505305.

\section{REFERENCES}

[1] WEN, BC.; ZHANG, YM.; REN, ZH.; SONG, NH.; XIN, LL. Nonlinear Vibration System with Nonlinear Inertia Force and Influence of Vibration on Rub and Wears, In: 6th WSEAS International Conference on Circuits, Systems, Electronics, Control \& Signal Processing 2007, Cairo, Egypt, 152-155.

[2] LI, XP.; TENG, YN.; XIN, LL.; WEN, BC. Experimental Investigation of Characteristics of Vibratory Compaction System with Different Water Saturation, Applied Mechanics and Materials 2010, 29-32, 1488-1493. https://doi.org/10.4028/www.scientific.net/amm.29-32.1488

[3] XIN, LL.; LIANG, JH.; WEN, BC. Dynamic Analysis of a Vabrating Conveyer with Inclination in Consideration of Material Combination Coefficient, Transactions of the Chinese Society for Agricultural Machinery 2009, 40(2), 87-90.

[4] HUANG, LP.; FAN, BC.; DONG, G. Mechanism of Drag Reduction Due to Spanwise Wall Oscillation in Turbulent Channel Flow, Journal of Nanjing University of Science and Technology(Natural Science) 2010, 34 (3), 361-366.

[5] JIA, JX.; ZHANG, DX.; YANG, DQ. Analysis and Computer Simulating on Potatoes Bruising of Vibrating Sieve in Potatoes Harvester, Transactions of the Chinese Society for Agricultural Machinery 2005, 36 (12), 67-70.

[6] JIA, JX.; ZHANG, DX.; HAO, XM.; LIU, HW. Parametric Modeling and Computer Simulation of Potato Harvester Parts, Transactions of the Chinese Society for Agricultural Machinery 2005, 36 (11), 64-67.

[7] ZHANG, J.; WEI, HA. Moving simulation on potato and soil separating by 4M-2 potato-harvester, Journal of Gansu Agricultural University 2009, (3), 153 -157.

[8] SHI, MM.; WEI, HA.; HU, ZQ.; LIU, X.; YANG, XP. Design on the 4U-1400 potato combine harvester, Agricultral Research in the Arid Areas 2014, 32 (1), 263-267.

[9] NIU, HH.; ZHAO, WY.; SHI, ZL. Simulation analysis on working performance of 4UM-1 potato harvester based on ADAMS, Journal of Gansu Agricultural University 2011, (3), 117-120.

[10] LIU, B.; ZHANG, DX.; LI, J. Design on MZPH-820 Single-row Potato Harvester, Transactions of the Chinese Society for Agricultural Machinery 2009. 40 (5), 81-86. 
[11] ZHANG, H.; WU, JM.; SUN, W.; LUO, T.; WANG, D.; ZHANG, JL. The design and experiment of 4UM-640 vibration potato digger, Agricultral Research in the Arid Areas 2014, 32(2), 264-268.

[12] SHI, LR.; WU, JM.; ZHAO, WY.; SUN, W.; WANG, D.; LI, H.; LIU, QW. Design and experiment on potato digger of disc ce-grate type, Transactions of the Chinese Society of Agricultural Engineering (Transactions of the CSAE) 2012, 28(24), 15-21.

[13] WU, JM.; LI, H.; SUN, W.; HUANG, XP.; SUN, BG. Design of Potato Digger in Poke Finger's Wheel Type, Transactions of the Chinese Society for Agricultural Machinery 2010, 41(12), 76-79.

[14] WEI, HA.; WANG, D.; LIAN, WX. Development of 4UFD-1400 type potato combine harvester, Transactions of the Chinese Society of Agricultural Engineering (Transactions of the CSAE) 2013, 29(1), 11-17.

[15] PLATT, HW.; CAMPBELL, AJ.; BIRT, I.; MACKINNON, B. Modifications of a Potato Harvester for Small Plot Field Research, American Potato Journal 1990, 67, 799-803. https://doi.org/10.1007/bf03044531

[16] WANG, FY. Discussion on the Structure of Passive Vibrating Wheel of 4U-2 Type Potato Harvester, Agricultural Science \&Technology and Equipment 2011, (6), 61-62.

[17] Sun, ZG. Development of 4U-2 Potato Lifter, Agricultural Science \&Technology and Equipment 2009, (3), 74-76.

[18] Gao, W.; Farahani, MR.; Aslam, A.; Hosamani, S. Distance learning techniques for ontology similarity measuring and ontology mapping, CLUSTER COMPUT 2017,20, 959-968. https://doi.org/10.1007/s10586-017-0887-3

[19] KANG, WS.; HALDERSON, JL. Development of a Vibratory Potato Digger for Small Farms, American Potato Journal 1991, 68, 557-568. https://doi.org/10.1007/bf02853709

[20] ROGER, CB. Impact Testing of Potato Harvesting Equipment, American Potato Journal 1993, 70, 244257.

[21] BENTINI, M.; CAPRARA, CR.; MARTELLI. Harvesting Damage to Potato Tubers by Analysis of Impacts recorded with an Instrumented Sphere, Biosystems Engineering 2006, 94(1), 75-85. https://doi.org/10.1016/j.biosystemseng.2006.02.007

[22] MCRAE, DC. A potato harvester delivery conveyor with automatic discharge height control, Potato Res 1974. 17, 138-151. https://doi.org/10.1007/bf02360378

[23] WANG, B.; HU, LL.; HU, ZC.; TIAN, LJ.; JI, FL.; MA, B. Damage mechanism study of chain-lever elevator sweet potato harvester, Journal of China Agricultural University 2014, 19(2), 174 -180.

[24] Gao, W.; Wang, W. The fifth geometric-arithmetic index of bridge graph and carbon nanocones, $J$ DIFFER EQU APPL 2017, 23, 100-109. https://doi.org/10.1080/10236198.2016.1197214

[25] VAN, CT.; SPRIET, Y.; VERSCHOORE, R.; SONCK, B. Quality assessment of anti-shock systems for potatoes, Potato Research 2005, 48, 35-48. https://doi.org/10.1007/bf02733680

Submitted: $\quad 27.7 .2017$

Accepted: $\quad 27.3 .2019$
Xin Lili $\bowtie$

Shenyang Agricultural University

engineering college

xinlilisss@163.com

Liang Jihui

Shenyang Ligong University School of

Automotive and Transportation

4516424@qq.com

Corresponding Author e-mail:

xinlilisss@163.com 